\title{
8-bromo-7-methoxychrysin targets NF-KB and FoxM1 to inhibit lung cancer stem cells induced by pro-inflammatory factors
}

\author{
Qing Yuan ${ }^{1 *}$, Min Wen ${ }^{1 *}$, Chang $\mathrm{Xu}^{2,3}$, A Chen ${ }^{2,3}$, Ye-Bei Qiu ${ }^{2,3}$, Jian-Guo Cao ${ }^{2,3}$, Jian-Song Zhang ${ }^{\bowtie}$, \\ Zhen-Wei Song1,2,3凶 \\ 1. Department of preclinical medicine, Medical College, Hunan Normal University, Changsha, 410013, China \\ 2. Department of Pharmaceutical Science, Medical College, Hunan Normal University, Changsha, 410013, China \\ 3. Key Laboratory of Study and Discover of Small Targeted Molecules of Hunan Province, Changsha 410013, China \\ * They contributed equally to this work. \\ $\bowtie$ Corresponding authors: Zhen-Wei Song, Jian-Song Zhang
}

(1) The author(s). This is an open access article distributed under the terms of the Creative Commons Attribution License (https://creativecommons.org/licenses/by/4.0/). See http://ivyspring.com/terms for full terms and conditions.

Received: 2018.09.23; Accepted: 2019.07.16; Published: 2019.08.28

\begin{abstract}
We have previously reported that 8-bromo-7-methoxychrysin (BrMC), a novel synthetic derivative of chrysin, was demonstrated anti-tumor activities against several human cancers, including lung cancer. Interaction between inflammation and cancer stem cell are recently increasingly recognized in tumorigenesis and progression. The purpose of this study was to investigate whether $\mathrm{BrMC}$ inhibits lung cancer stemness of $\mathrm{H} 460$ cells induced by inflammatory factors (TGF- $\beta$ combined with TNF- $\alpha$ ) and its potential mechanism. Our results showed that BrMC inhibited lung cancer stemness, as validated by enhanced self-renewal ability, higher in vitro tumorigenicity, and increased expression of CD133, CD44, Bmil and Oct4 in H460 cells administered TNF- $\alpha$ after prolonged induction by TGF- $\beta$, in a concentration-dependent manner. Both NF-KB inhibition by SN50 and FoxMl suppression by thiostrepton (THI) prompted the inhibition of $\mathrm{BrMC}$ on lung CSCs. Conversely, overexpression of NF-KBp65 significantly antagonized the above effects of BrMC. Meanwhile, overexpression of FoxMl also significantly compromised BrMC function on suppression of FoxMl and NF-KBp65 as well as stemness of lung CSCs. Our results suggest that activation of NF-KB and FoxMl by cytokines facilitate the acquisition CSCs phenotype, and compromise the chemical inhibition, which may represent an effective therapeutic target for treatment of human lung cancer. Moreover, $\mathrm{BrMC}$ may be a potential promising candidate for targeting NF-KB/ FoxMl to prevent the tumorigenesis under inflammatory microenvironment.
\end{abstract}

Key words: lung cancer; cancer stem cell; tumorigenesis; inflammatory factor; NF-kB; FoxM1

\section{Introduction}

Lung cancer is the leading cause of cancer-related death [1] and around $85 \%$ of new diagnosed lung cancer is non-small-cell lung carcinoma (NSCLC) [2]. In spite of chemotherapy and targeted therapies available, a 5-year survival rate for NSCLC is only $18 \%$ [3-5]. Therefore, further exploration of new therapeutic agents is necessary to improve therapeutic outcomes in NSCLC.

Many clinical evidences uncovered the etiological landscapes of lung carcinogenesis, among which the inflammation cytokines are contributing the risk to the development and subsequent progression [6, 7]. Especially, exists data suggest that tumor necrosis factor-alpha (TNF-a) and transforming growth factor-beta (TGF- $\beta$ ) are both the most potent inducer of lung cancer promoting microenvironment $[8,9]$. Presence of TGF- $\beta$ treatment potentiates the Epithelial-mesenchymal transition (EMT), which is a key step to early cancer metastasis [10]. Remarkably, TNF-a can drive adaptive response to epidermal growth factor receptor (EGFR) inhibition in NSCLC, which is responsible for the resistance any failure of therapy in clinics [11]. 
Many studies have recently demonstrated that cancer stem cells (CSC) play a vital role in initiation and drive aggressive behavior in multiple cancers [12, 13], as while as lung CD133+ CSC constitute tumor-initiating activity in NSCLC $[14,15]$. Specially, this CSC characteristics, namely 'stemness', can be highly induced by chronic exposure to TNF- $\alpha$ combined with TGF- $\beta$ [16], which is tightly involved by NF-kB signaling in cytokine production and immune responses. Recent discovery demonstrate NF-kB significantly involve the capability of CSCs [17] and is highly associated with poor survival in NSCLC [18]. FoxM1 is a member of the forked box transcription factor family, which has been widely reported in regulating the stemness of CSC [19] and cause progression in tumorigenesis [20]. Our previous data show that upregulation of FoxM1 expression promote the acquisition of CSC stem properties in NSCLC [21]. Therefore, the NF-KB and FoxM1 are strongly associated with stemness of lung cancer, which may provide vital therapeutic targets in preventing human NSCLC.

Initiation and progression of tumorigenesis rely on the interaction of cancer stem cells with the tumor microenvironment [22], which are recruited by cytokine activity driven by inflammation or produced by cancer cells. Both TNFa and TGF- $\beta$ have been shown to activate oncogenic pathway [23] and act on the NSCLC microenvironment [24]. But, the acquisition of CSC features and consequent regulation on pathway derived from cytokine activity are still unclear. Our recent study demonstrated that 8-bromine-7-methoxychrysin (BrMC), a novel analogue of chrysin inhibits the malignant potential of cancer stem cells of hepatocellular carcinoma in vitro and in vivo [12]. BrMC also can effectually reverse the M2 polarization of tumor associated macrophages by inhibiting NF-kB activation [25]. For this reason, the purpose of this study was to evaluate whether BrMC can inhibit lung cancer stemness in $\mathrm{H} 460$ cells administered TNF- $\alpha$ after prolonged induction by TGF- $\beta$.

\section{Material and Methods}

\section{Reagents}

BrMC was synthesized according to previous described [26]. The molecular formula is $\mathrm{C}_{16} \mathrm{H}_{11} \mathrm{BrO}_{4}$, the character is yellow like powder, the molecular weight is 347 , and its purity is $99.5 \%$ by HPLC. BrMC was diluted with dimethyl sulfoxide (DMSO) to 10 $\mathrm{mmol} / \mathrm{L}$, the desired concentration was diluted to by DMEM medium before application. TGF- $\beta$ and TNF- $\alpha$ from Sino Biological (Beijing,China). NF-кBP65 inhibitors (SN50) and FoxM1 specific inhibitors, thiostrepton (THI), are purchased from Sigma-Aldrich
(St. Louis, MO, USA). NF-kBp65 antibody was purchased from Abcam (Burlingame, CA, USA). The Rabbit anti human $\beta$-actin monoclonal antibody was derived from Proteintech (Chicago, USA). The following antibodies were purchased from CST (Massachusetts, USA): Anti FoxM1, CD44, Oct4, CD133 antibodies. The recombinant adenovirus containing pHBad-MCMV-GFP plasmids and pHBad-MCMV-GFP-NF-kBp65 plasmids (virus titer: $10^{10} \mathrm{pfu} / \mathrm{mL}, 2 \mathrm{~mL}$ ) was prepared by Han Heng Biotech Corp (Shanghai, China). The FoxM1expressing lentivirus, ENi.s (enhanced infection reagents and Polybrene were purchased from Genechem (Shanghai, China), puromycin purchased from Jikai gene company, Catalog No.REVG0002, Shanghai, China. Opti-MEM reagent is the product of Invitrogen (China, Shanghai).

\section{Cell culture and Treatment}

H460 cell line obtained from the Cell Bank of Chinese Academy of Sciences (China), were maintained according to previously described methods [27]. For cell modeling, the cells were exposed to TGF- $\beta$ ( $5 \mathrm{ng} / \mathrm{mL}$ ) for 30 days followed by TGF- $\beta$ (5 ng/mL) combined with TNF- $\alpha$ (5, 10 $\mathrm{ng} / \mathrm{mL}$ ) for 24 hours. For drug intervention, cells were administered BrMC at different amounts (1.0, 5.0 and $10.0 \mu \mathrm{mol} / \mathrm{L})$ alone or BrMC $(5.0 \mu \mathrm{mol} / \mathrm{L})$ plus SN50 $(10.0 \mu \mathrm{mol} / \mathrm{L})$ or BrMC $(5.0 \mu \mathrm{mol} / \mathrm{L})$ plus THI $(10.0 \mu \mathrm{mol} / \mathrm{L})$ for $24 \mathrm{~h}$. To explore mechanisms, H460 cells expressing NF-kBp65 or FoxM1 were treated with or without BrMC $(5.0 \mu \mathrm{mol} / \mathrm{L})$ for $24 \mathrm{~h}$.

\section{Cell transduction}

For NF-kBp65 cDNA transduction, H460 cells grown in 24-well culture plates to $40-50 \%$ confluence were incubated overnight. Subsequently, they were infected with adenoviral particles packaged with control pHBAd-MCMV-GFP or pHBAd-MCMV-GFPNF-kBp65 plasmids, respectively, cultured with Opti-MEM using the enhanced infection solution (ENi.s; GeneChem, China). Following $4 \mathrm{~h}$ of transduction, DMEM containing 10\% FBS was added to replace the transduction medium. The cells were then incubated for an additional $48 \mathrm{~h}$, prior to gene and protein level assessments. For stable expression of FoxM1 gene, H460 cells were infected with lentiviral particles containing full-length FoxM1 (NM_021953) or control vectors (GV358) using the enhanced infection solution (ENi.s; GeneChem, China). H460 cells stably expressing FoxM1 were isolated by puromycin selection.

\section{Sphere formation assay}

Single-cells were seeded into ultra-low attachment 24-well plates (Corning, USA) at $10^{3}$ 
cells $/ \mathrm{ml}$ in serum-free stem cell conditional medium. After a 6 day incubation period, spheroids were counted, to derive the sphere-formation rate by dividing the total number of spheres obtained by that of live cells seeded multiplied by one-hundred.

\section{Soft Agar Colony Assay}

H460 cells administered TNF- $a$ after prolonged induction by TGF- $\beta$ were seeded into each 24 -well plate in different conditions culture medium / agarose (at a 1:1 ratio) containing 1.2\% agarose base layer and $0.7 \%$ agarose top layer. Cell culture the different conditions medium was removed and replaced periodically every 2 to 3 days. Following 12 days of incubation, cells were imaged under an inverted fluorescent microscope (Olympus, Japan). Individual stained colonies in each well were counted and the colony formation rate was calculated as follows: colony number / (number of cells seeded $x$ each well efficiency), where each well is equivalent to the colony number divided by the number of cells seeded in the control medium.

\section{Western Immunoblot}

Immunoblot was carried out according to a previous report [21]. The primary antibodies used for membrane incubation targeted Bmi1, Oct4, CD133, CD44, NF-kBp65 and FoxM1. The membranes were further incubated with appropriate HRP-conjugated secondary antibodies. Immunoreactive bands were revealed by enhanced chemiluminescence. The UN-SCAN-IT software (Silk Scientific) was used for densitometry analysis, with $\beta$-actin serving as an internal reference.

\section{Statistical analysis}

Experimental data were analyzed using SPSS 20.0 for Windows (SPSS Inc, Chicago, IL). Data representing mean $\pm S D$ were subjected to one-way ANOVA. First, the homogeneity of variance was determined. We used LSD to analyze pair wise comparisons among the groups. In the event of incomplete variance, the control and the experimental groups were analyzed with Tukey's test. A probability (P value) of less than 0.05 suggested statistical significance.

\section{Results}

Treatment of TGF- $\beta$ combined with TNF- $\alpha$ promotes lung cancer stemness in $\mathbf{H 4 6 0}$ cells.

To explore the association between cancer stem cell and inflammatory cytokines [28], a cell model was established by long term incubation of cytokines. NSCLC cell line H460 cells were exposed to TGF- $\beta$ (5 $\mathrm{ng} / \mathrm{mL}$ ) for 30 days followed by TGF- $\beta$ ( $5 \mathrm{ng} / \mathrm{mL}$ ) combined with TNF-a $(5,10 \mathrm{ng} / \mathrm{mL})$ for 24 hours. As shown in Supplementary Fig. 1, the incubated cells exhibited a typical morphological change of epithelial to mesenchymal transition (EMT), including loss of cuboidal appearance [29]. As shown in Fig. 1 (A D), TGF- $\beta$ ( $5 \mathrm{ng} / \mathrm{mL})$ chronic exposure or in combination with TNF-a $(5,10 \mathrm{ng} / \mathrm{mL})$ caused an increase of sphere-forming compared with $\mathrm{H} 460$ cells cultured in complete medium (Fig. 1E). To further grow out the cancer stem cells from there induced cells, suspension culture system was employed [30] to select the CSCs for following experiments. As shown in Fig. F I, the single cells from cell sphere apparently hold higher colony-forming capability and even acquired more efficiency after long term incubation in pro-inflammatory factors medium (Fig. 1J). Western blot results showed that the combined treatment of TGF- $\beta$ and TNF- $\alpha$ could cooperatively increase the expression level of CSCs markers, CD144 and CD44 proteins (Fig. 1K, Supplementary Fig. 2). The expression level of pluripotent transcription factor Bmi1 and Oct 4 also increased (Fig. 1K, Supplementary Fig. 2). In addition, TGF- $\beta$ chronic exposure or in combination with TNF-a transient treatment led to upregulation of the expression of NF-kBp65 and FoxM1 (Fig. 1K). These results also showed that co-treatment of TGF- $\beta$ combined with TNF-a promote the acquisition of stemness in NSCLC H460 in a dose dependent manner.

\section{BrMC inhibits stemness of $\mathrm{H460}$ cells induced by proinflammatory cytokines}

Our data here showed cytokines incubation increased the acquisition of stem cell phonotype in term of stemness. To determine whether BrMC can inhibit lung cancer stemness of $\mathrm{H} 460$ cells induced by proinflammatory cytokines, we used BrMC (1.0, 5.0, $10.0 \mu \mathrm{mol} / \mathrm{L})$ to incubation $\mathrm{H} 460$ cells administered TNF- $\alpha$ after prolonged induction by TGF- $\beta$. As expected, BrMC effectively reduced sphere-forming (Fig. $2 \mathrm{~A} \sim \mathrm{E}$ ) and colony-forming capability (Fig. $2 \mathrm{~F} \sim \mathrm{J}$ ) induced by proinflammatory cytokines, compared with control cells. Furthermore, BrMC could downregulate the expression of CD144, CD44, Bmi1 and Oct4 (Fig. 2K, Supplementary Fig. 3). Meanwhile, BrMC notably decreased expression levels of NF-kBp65 and FoxM1 proteins, in a concentration-dependent manner (Fig. 2K, Supplementary Fig. 3). These data demonstrated that although the stemness was improved by proinflammatory cytokines treatment, BrMC can still contribute to a dose-dependent inhibition on the stemness of CSCs and downregulation of NF-KBp65 and FoxM1 expressions. 

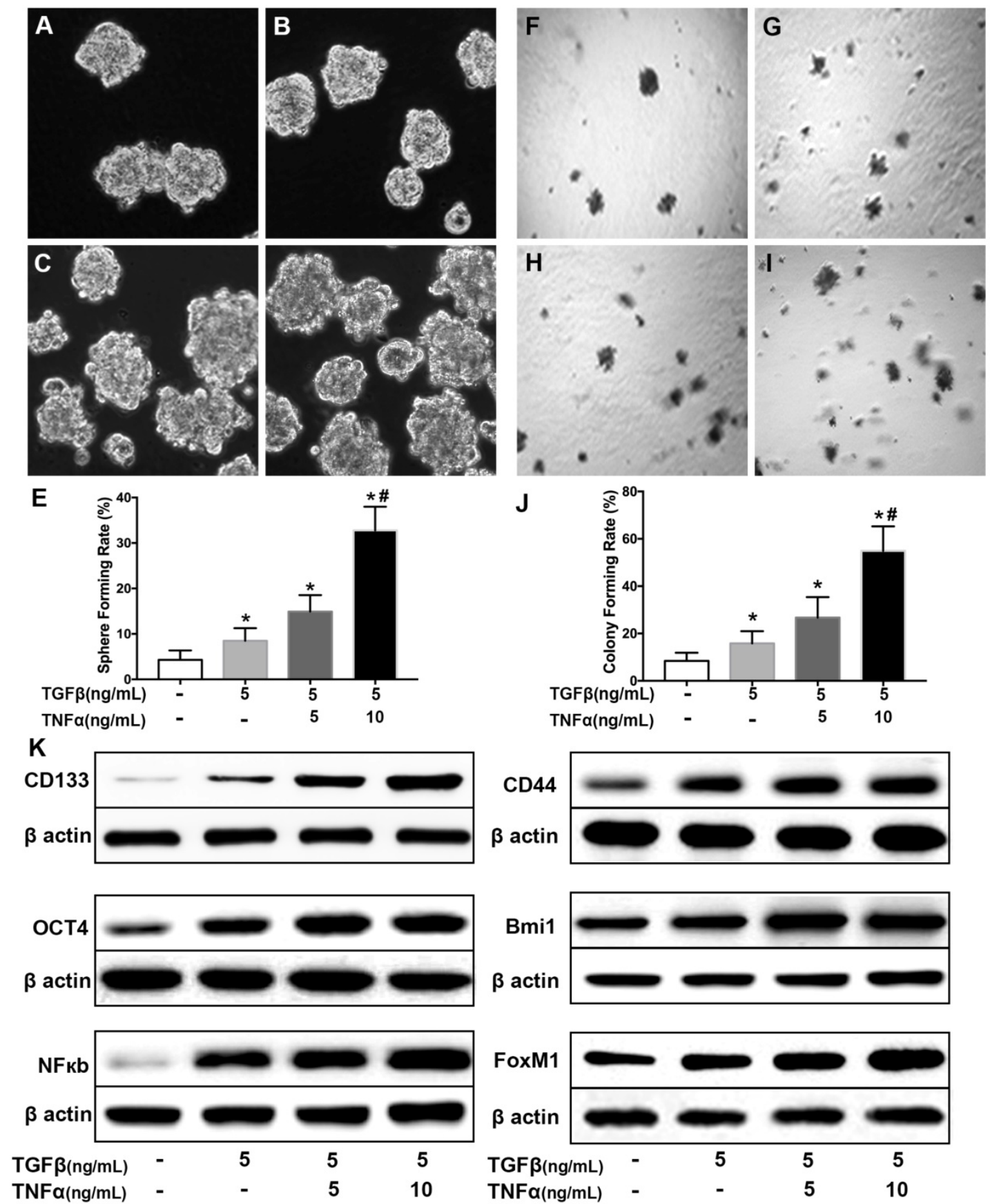

Figure 1. Co-treatment of TGF- $\beta$ and TNF- $\alpha$ induces lung cancer stemness in $\mathbf{H} 460$ cells. H460 cells were exposed to different concentrations of TNF- $\alpha$ ( 5 , 10 $\mathrm{ng} / \mathrm{mL})$ for $24 \mathrm{~h}$ following treated with TGF- $\beta(5.0 \mathrm{ng} / \mathrm{mL})$ for $30 \mathrm{~d}$. Sphere forming rate $(A \sim E)$ and colony forming rate $(F \sim J)$ were evaluated. Stemness appearance was determined by lung cancer stem cell makers CD133, CD44, Bmil and Oct4 through western blot (K). Activation of NF-KB pathway (NF-KBp65) and human proto-oncogene FoxM1 were analyzed by western blot $(K) .{ }^{* P}<0.05$, vs untreated cells; $\# P<0.05$, vs treated with TGF- $\beta$ only.

\section{SN50 cooperated with BrMC to inhibit stemness of $\mathrm{H} 460$ cells induced by proinflammatory cytokines}

Activation of NF-kB involves the progression of lung cancer [17]. To evaluate whether down-regulation of NF-kBp65 eliminate the increased stemness characteristics induced by proinflammatory cytokines, H460 CSCs were treated by specific inhibitor SN50 together with BrMC. Although H460
CSCs gained higher stemness characteristics (Fig. 1) by TGF- $\beta$ incubation following administered TNF- $\alpha$, as shown in Fig. 3, stemness characteristics were significantly reduced in presence of SN50 or BrMC. SN50 (10.0 $\mathrm{mol} / \mathrm{L})$ significantly inhibited CSCs spare (Fig. 3A $\sim$ E) and colony forming capability (Fig. $3 \mathrm{~F} \sim$ J), and decreased the expression levels of CD144, CD44, Bmi1 and Oct4 (Fig. 3K, Supplementary Fig. 4). Remarkably, in combination of BrMC and SN50 enhanced the inhibition of stemness characteristics as 
well as down-regulation of FoxM1 expression (Fig. 3K, Supplementary Fig. 4). However, with cooperativity between downregulation of FoxM1 and BrMC affection, compared the SN50 only, the lower concentration of BrMC alone significantly inhibited stemness characteristics and reduced the expression of NF-KBp65 and FoxM1. It suggests that inhibition function of BrMC may be through downregulation of NF-kBp65 expression in H460 CSCs.
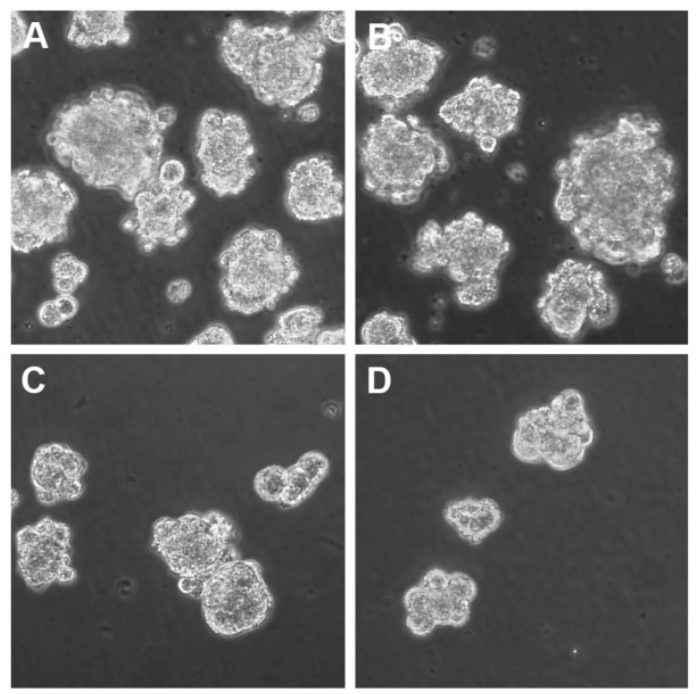

E
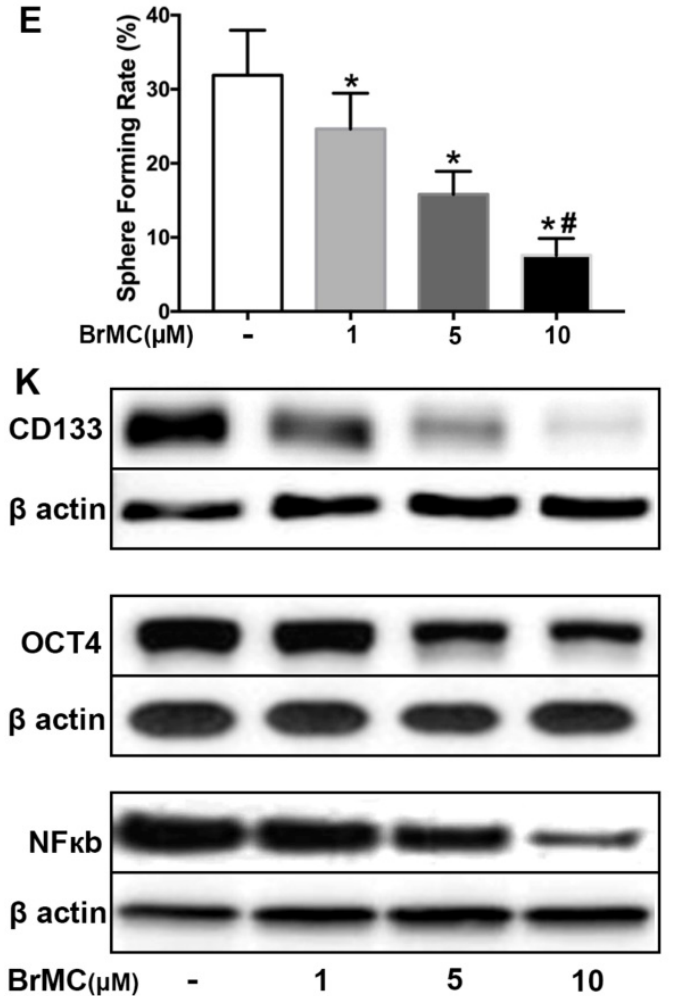

\section{Co-treatment of thiostrepton and BrMC cooperatively inhibited stemness of $\mathrm{H} 460$ cells induced by proinflammatory cytokines}

Recent reports identified up-regulation of FoxM1 involved initiation of lung tumorigenesis, which raised a potential pharmacological target [31]. To assess the role of FoxM1 downregulation in inhibitory effects of BrMC on stemness of $\mathrm{H} 460$ cells induced by proinflammatory cytokines, H460 cells administered TNF- $\alpha$ after prolonged induction by TGF- $\beta$ were
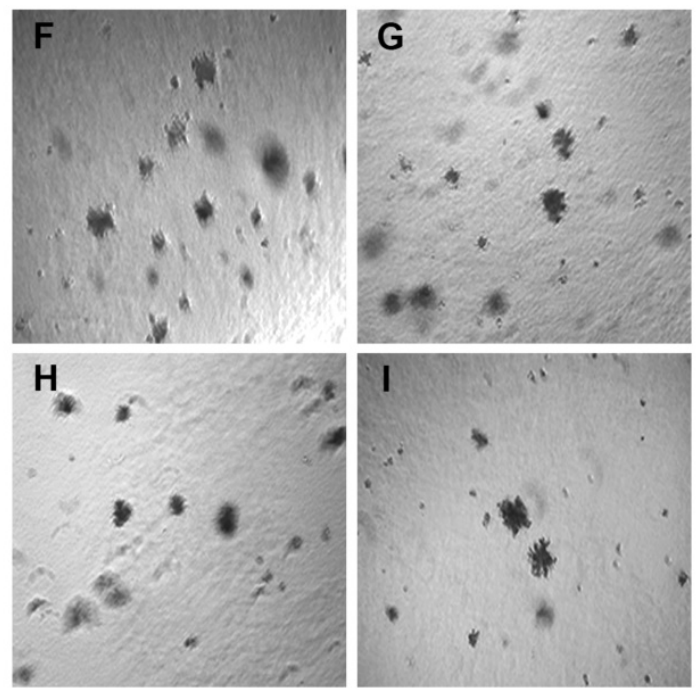

$\mathbf{J}$
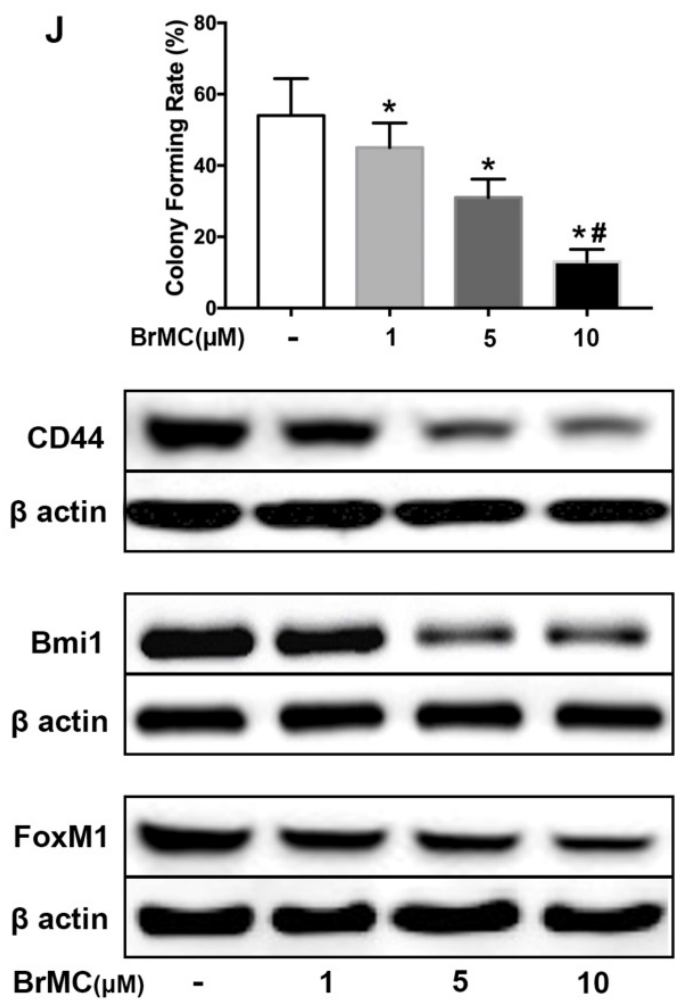

Figure 2. Effects of BrMC on stemness of $\mathbf{H 4 6 0}$ cells induced by pro-inflammatory cytokines. H460 CSCs after chronic exposure to TGF- $\beta$ followed by TNF- $\alpha$ incitation were treated with $\mathrm{BrMC}$. The inhibition of $\mathrm{BrMC}$ was tested by cancer sphere forming (A E) and soft ager colony forming ( $\mathrm{F} \sim)$ with single $\mathrm{CSC}$ suspension. The effection on stemness capacity was evaluated by expressions of lung stem cell markers CD133, CD44, Bmil and Oct4 via western blot (K). The regulation on activation of NF-KB signaling and proto-oncogene FoxM1 were analyzed by western blot in CSCs under different concentrations of $B r M C(1,5,10 \mu M) .{ }^{*} P<0.05, v s$ untreated cells; $\# P<0.05$, vs treated with BrMC only. 
treated with thiostrepton and BrMC alone or in combination. The cooperative inhibitory effect of BrMC combined with thiostrepton on stemness of H460 cells induced by proinflammatory, including sphere-forming (Fig. 4A $\sim \mathrm{E}$ ) and colony-forming capability (Fig. $4 \mathrm{~F} \sim \mathrm{J}$ ) as well as expression of CD144, CD44, Bmi1 and Oct4 were shown (Fig. 4k, Supplementary Fig. 5). Interestingly, BrMC (5.0 $\mu \mathrm{mol} / \mathrm{L})$ and thiostrepton $(10.0 \mu \mathrm{mol} / \mathrm{L})$ alone or in combination significantly reduced expression of FoxM1 protein, accompanied by downregulation of
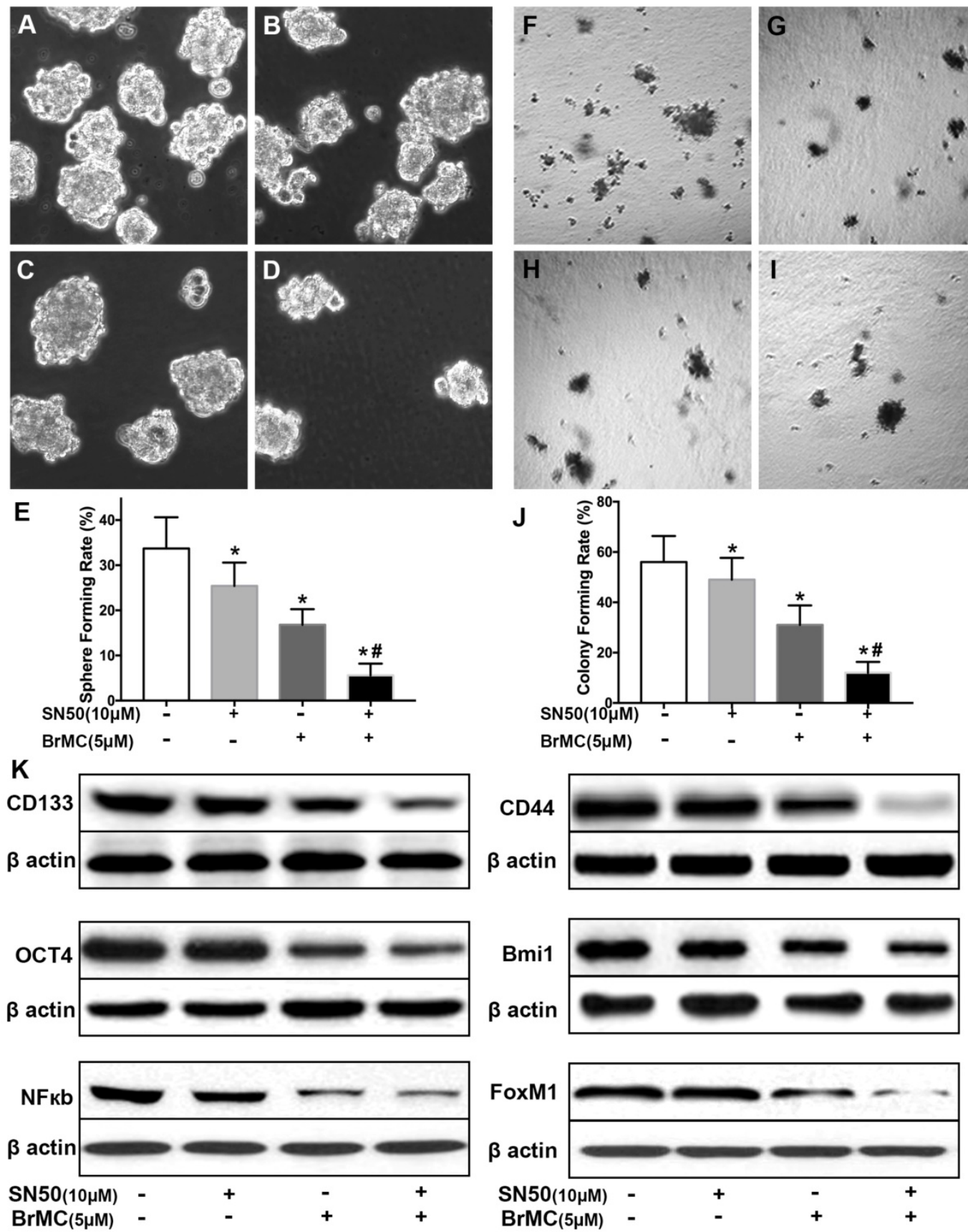

NF-kBp65 expression (Fig. 4k). These results suggest that inhibitory effects of BrMC on stemness of H460 cells induced by proinflammatory cytokines may be required for downregulation of FoxM1 expression.

\section{Overexpression of NF-kBp65 weakens inhibitory effects of BrMC on stemness of $\mathbf{H} 460$ cells induced by inflammatory factors}

In order to corroborate whether NF- $\mathrm{kB}$ expression is involved in the BrMC inhibition, CSCs after incubation of proinflammatory cytokines were
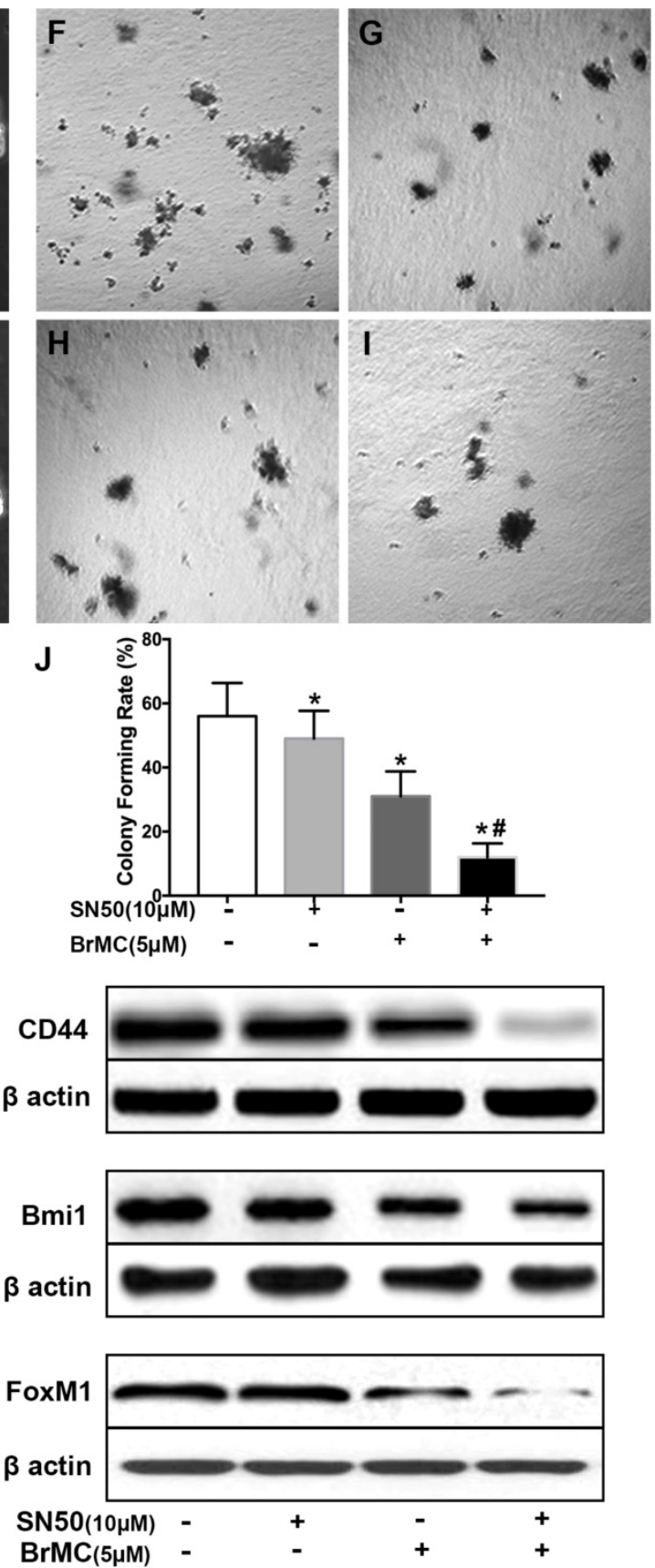

Figure 3. Effects of SN50 on inhibition of stemness of $\mathbf{H} 460$ cells induced by proinflammatory cytokines by BrMC. In presence $(+)$ or absence (-) of SN50, NF-KB signaling in $\mathrm{H} 460 \mathrm{CSCs}$ was regulated and inhibition of $\mathrm{BrMC}$ was determined. Stemness appearance of CSCs were evaluated by sphere forming assay (A E) and colony forming assay $(\mathrm{F} \sim \mathrm{J})$. Expressions of CD 133, CD44, Bmil and Oct4 as well as NF-KBp65 and FoxM1 were analyzed by western blot (K). ${ }^{*} P<0.05$, vs untreated cells; $\# P<0.05$, vs treated cells by SN50 $(10.0 \mu \mathrm{mol} / \mathrm{L})$. 
used to overexpress NF-kBp65 via lentiviral vectors. With overexpression of NF-KBp65, stemness characteristics and BrMC inhibition were evaluated. As shown in Fig. 5, the overexpression of NF-kBp65 promoted the sphere (Fig. $5 \mathrm{~A} \sim \mathrm{E}$ ) and colony formation (Fig. $5 \mathrm{~F} \sim \mathrm{J}$ ), as well as increased expression of CD144, CD44, Bmi1 and Oct4 in the treated H460 CSCs (Fig. 5K, Supplementary Fig. 6). In addition, overexpression of NF-kBp65 could substantially
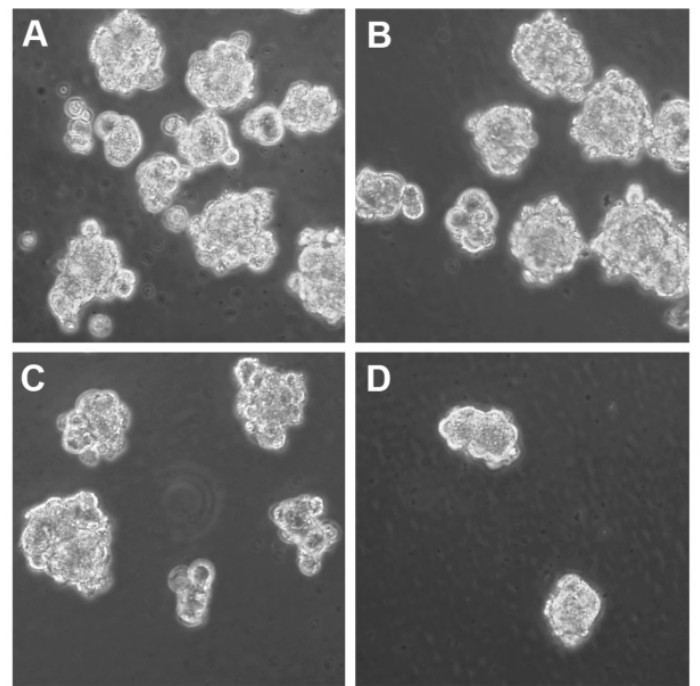

E

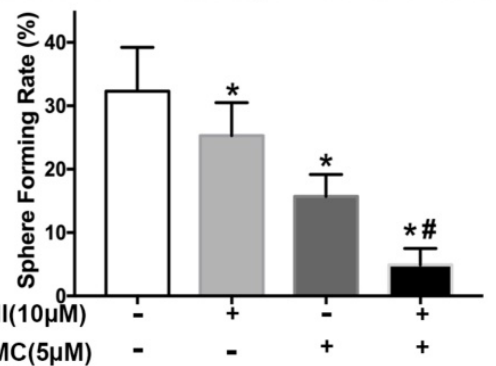

K
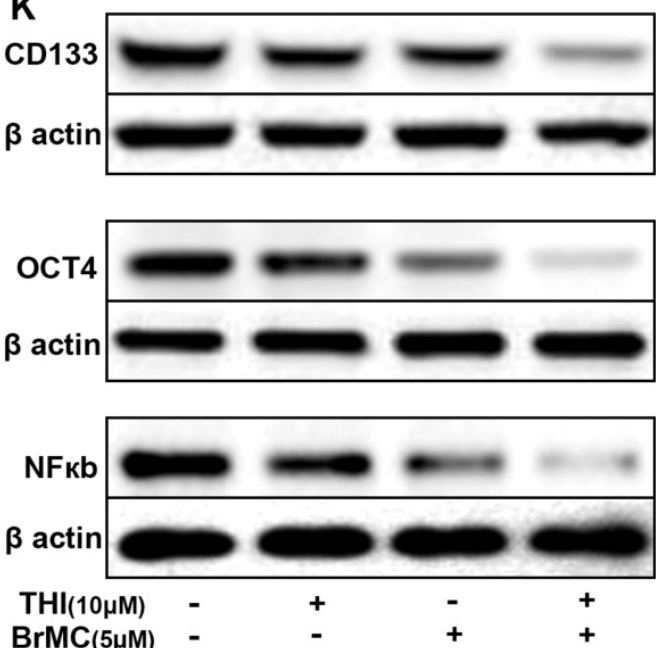

antagonize inhibitory effects of BrMC on sphere formation (Fig. 5E), colony formation (Fig. 5J) and expression of CD144, CD44, Bmi1 and Oct4 (Fig. 5K) in $\mathrm{H} 460$ cells administered TNF- $\alpha$ after prolonged induction by TGF- $\beta$. These results indicate that inhibitory effects of BrMC on stemness of H460 cells induced by proinflammatory cytokines may be dependent on downregulation of NF-kBp65 expression.
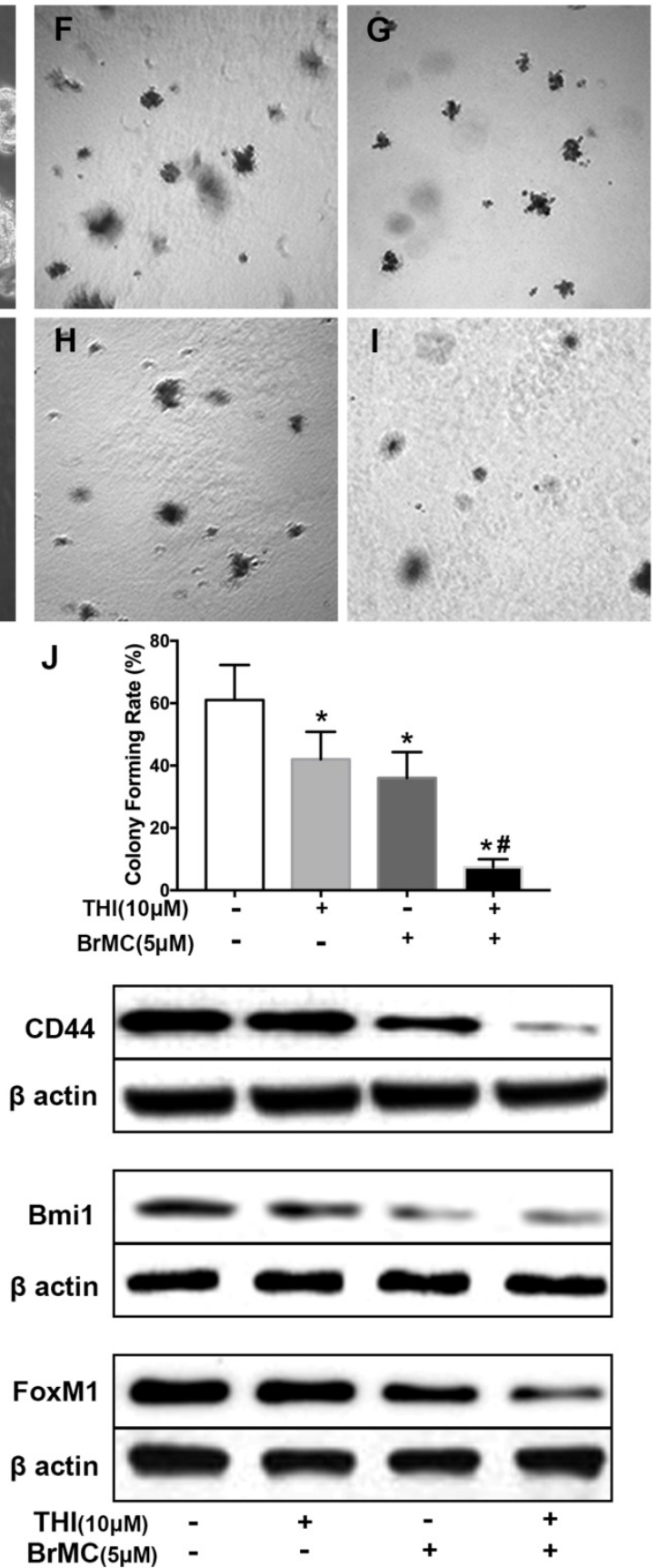

Figure 4. Effects of thiostrepton on inhibition of stemness of $\mathbf{H 4 6 0}$ cells induced by proinflammatory cytokines by BrMC. H460 cells by administered TNF- $\alpha$ following chronic exposure to TGF- $\beta$ were treated with thiostrepton (THI, $10.0 \mu \mathrm{mol} / \mathrm{L})$ or BrMC $(5.0 \mu \mathrm{mol} / \mathrm{L})$ or both. Representative formed sphere (A D) and cell colony $(\mathrm{F} / \mathrm{l})$ show the CSCs stemness capacity, and bar graph (E, J) show the rate individually. In presence (+) or absence $(-)$ of thiostrepton, expressions of stem cell markers CDI33, CD44, Bmil and Oct4 were analyzed by western blot (K). Inhibition of BrMC on CSCs was determined together with (+) or without (-) THI. Involvement of NF-KBp65 signaling and proto-oncogene FoxM1 were evaluated by WB. ${ }^{*} P<0.05$, vs untreated cells. $\# P<0.05$, vs treated cells with THI only. 

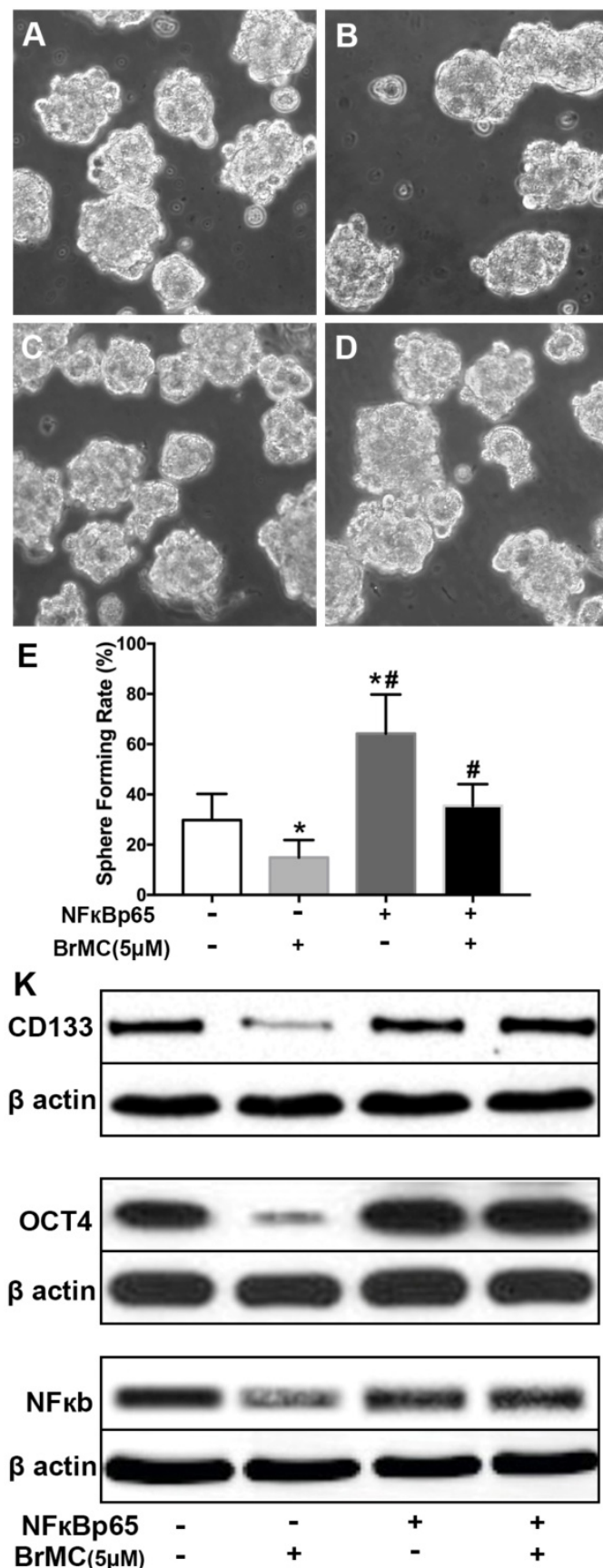
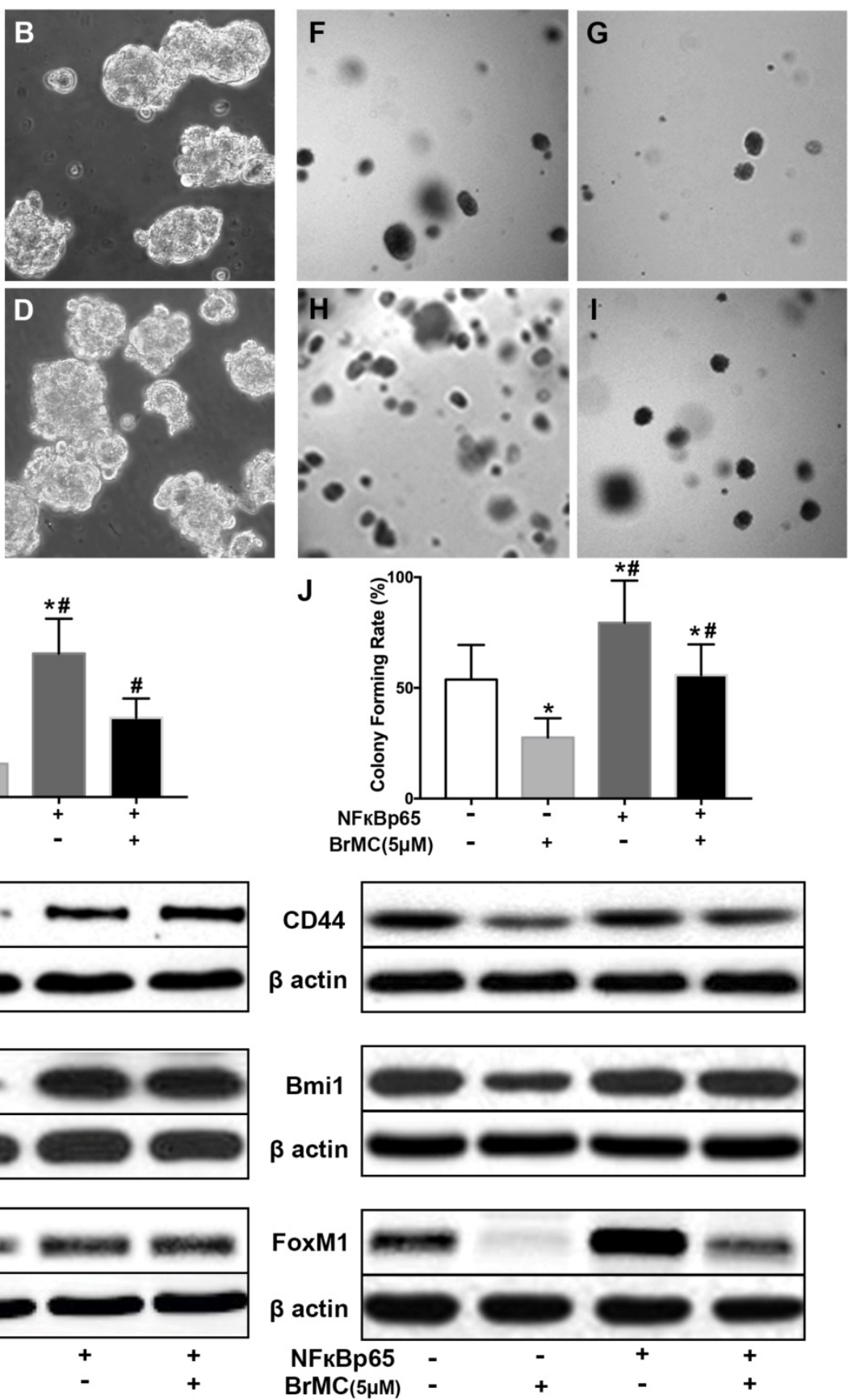

Figure 5. Effects of overexpression of NF-kBp65 on inhibition of stemness of $\mathbf{H} 460$ cells induced by proinflammatory cytokines by BrMC. With chronic exposure to TGF followed by incubation of TNF- $\alpha$, H460 cells were introduced NF-KBp65 by lentivirus GFP vectors. H460 CSCs expressing NF-KBp65 (+) or empty vector (-) were treated with $(+)$ or without $(-) B r M C(5.0 \mu \mathrm{mol} / \mathrm{L})$. Then, those CSCs were used to perform sphere forming (A E) in suspension culture and soft agar colony formation assay (F J). Expressions of CD133, CD44, Bmil and Oct4 as well as NF-KBp65 and FoxMl were analyzed by western blot (K). ${ }^{* P}<0.05$, vs vector control; $\# P<0.05$, vs $\mathrm{H} 460$ cells with vector treated by BrMC only.

\section{Overexpression of FOXMI weakens inhibitory effects of BrMC on stemness of $\mathrm{H} 460$ cells induced by proinflammatory cytokines}

FoxM1 is critical in the tumorigenesis, which is thought to be a potential target for inhibition the self-renewal of CSCs. In above results (Fig 1K), FoxM1 was boost by the introduction of proinflammatory cytokines in H460 cells, which may beneficial for the acquisition of stamens in CSCs. To confirm whether
BrMC target to FoxM1 in the inhibition of CSCs self-renewal, lentivirus vector was employed to fulfill the overexpression of FoxM1 in H460 cells after induction by TNF- $\alpha$ and TGF- $\beta$. Compared to empty vector, the overexpression of FoxM1 promoted the self-renewal activity of H460 CSCs, both in the sphere formation (Fig. 6 A, C, E) and colony formation capacity (Fig. 6 F, H, J). Meanwhile, with FoxM1 overexpression, CSCs characteristics were enhanced as the stem cell markers CD144, CD44, Bmi1 and Oct4 
were promoted (Fig. 6K, Supplementary Fig. 7). Specially, the NF-KB pathway was activated in the presence of raised FoxM1 abundance (Fig. 6K, Supplementary Fig. 7). As hypothesized, abnormal overexpression of FoxM1 compromised the inhibition of BrMC on stemness capacity. The efficiency of sphere formation (Fig. 6 B, D, E) and colony forming units (Fig. 6 G, I, J) was slightly recovered. In addition, overexpression of FoxM1 could reverse inhibitory function of BrMC on the expression of CD144, CD44, Bmi1 and Oct4 (Fig. 6K, Supplementary Fig. 7). These results support that down-regulation of FoxM1 expression involved the inhibitory effects of BrMC on stemness of $\mathrm{H} 460$ cells.
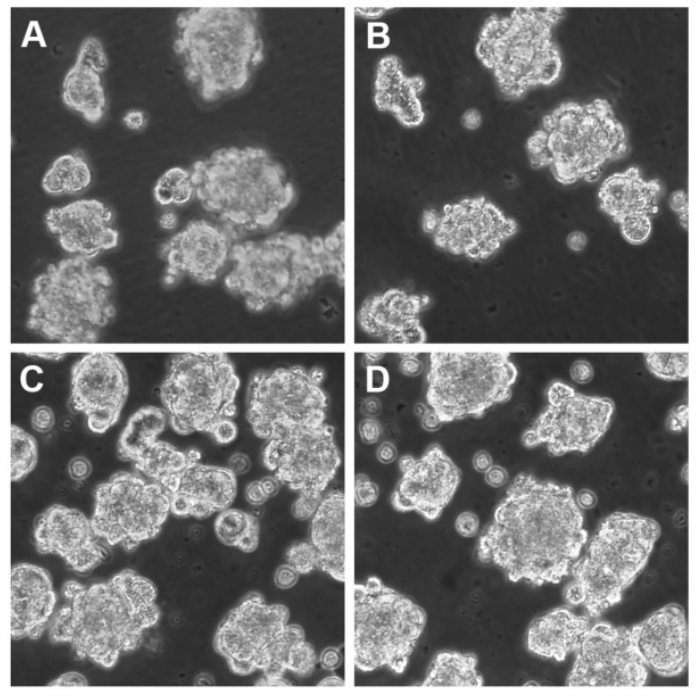

E
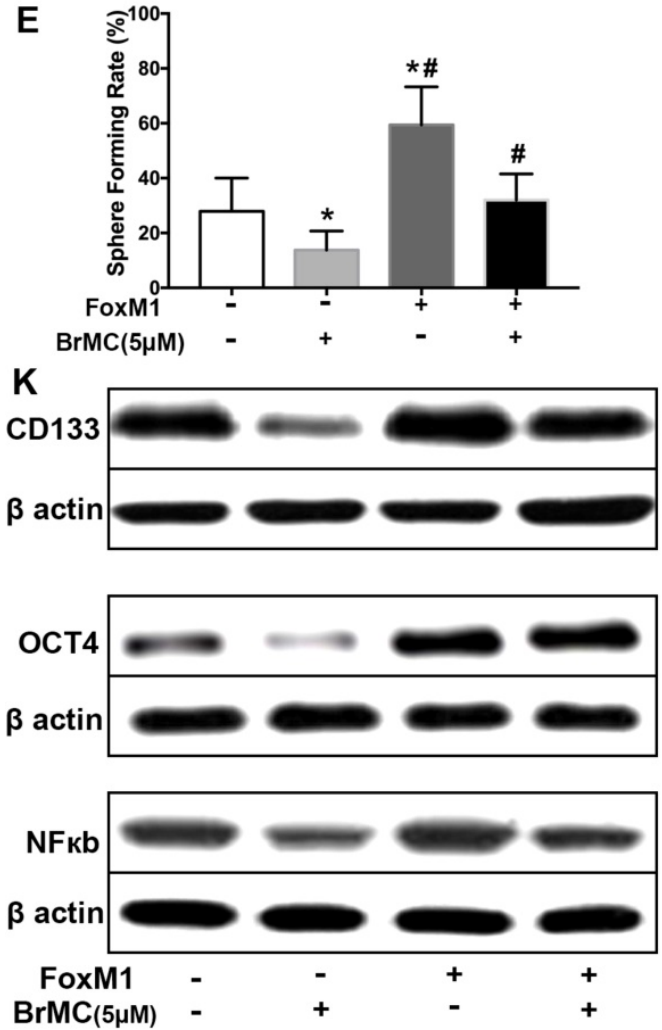
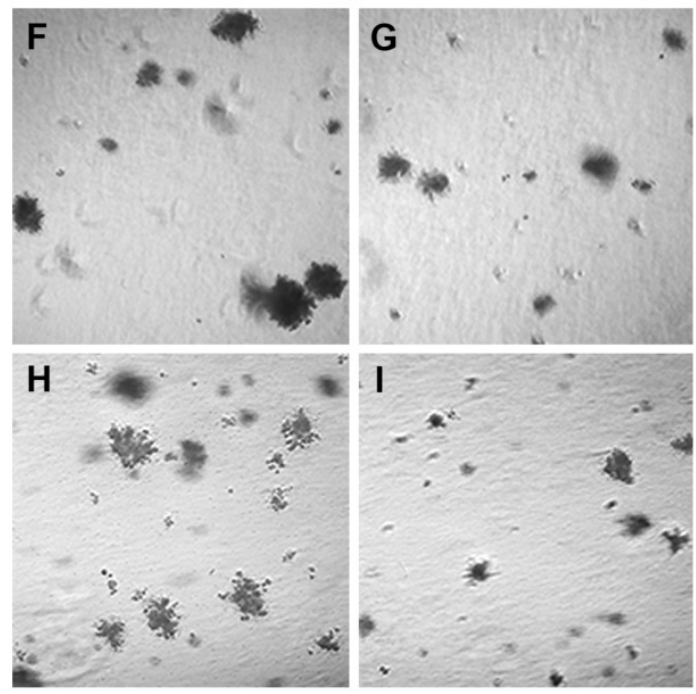

$\mathrm{J}$
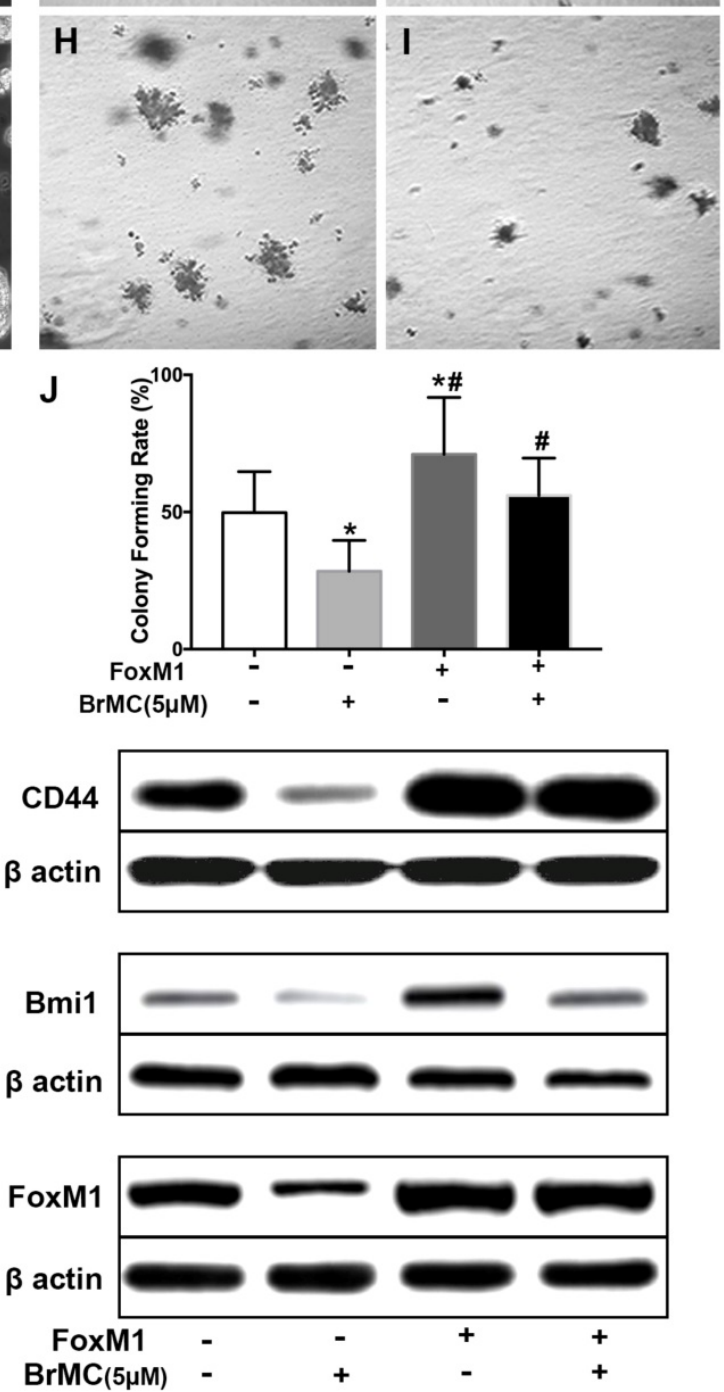

Figure 6. Effects of overexpression of FoxMl on inhibition of stemness of $\mathbf{H 4 6 0}$ cells induced by proinflammatory cytokines by BrMC. With chronic exposure to TGF followed by incubation of TNF-a, H460 cells were introduced FoxMl by lentiviral GFP vectors. H460 CSCs expressing FoxMl (+) or empty vector (-) were treated with $(+)$ or without $(-) \mathrm{BrMC}(5.0 \mu \mathrm{mol} / \mathrm{L})$. Sphere forming $(\mathrm{A} \sim \mathrm{E})$ in suspension culture and soft agar colony formation assay $(\mathrm{F} \sim \mathrm{J})$ with single CSCs suspension were performed to evaluate the stemness capacity. Stem cell markers CD133, CD44, Bmil and Oct4 were analyzed by western blot (K), as well as NF-KBp65 activity and FoxMl expression were tested. ${ }^{*} P<0.05$, vs vector control; $\# P<0.05$, vs $\mathrm{H} 460$ cells with vector treated by $\mathrm{BrMC}$ only. 


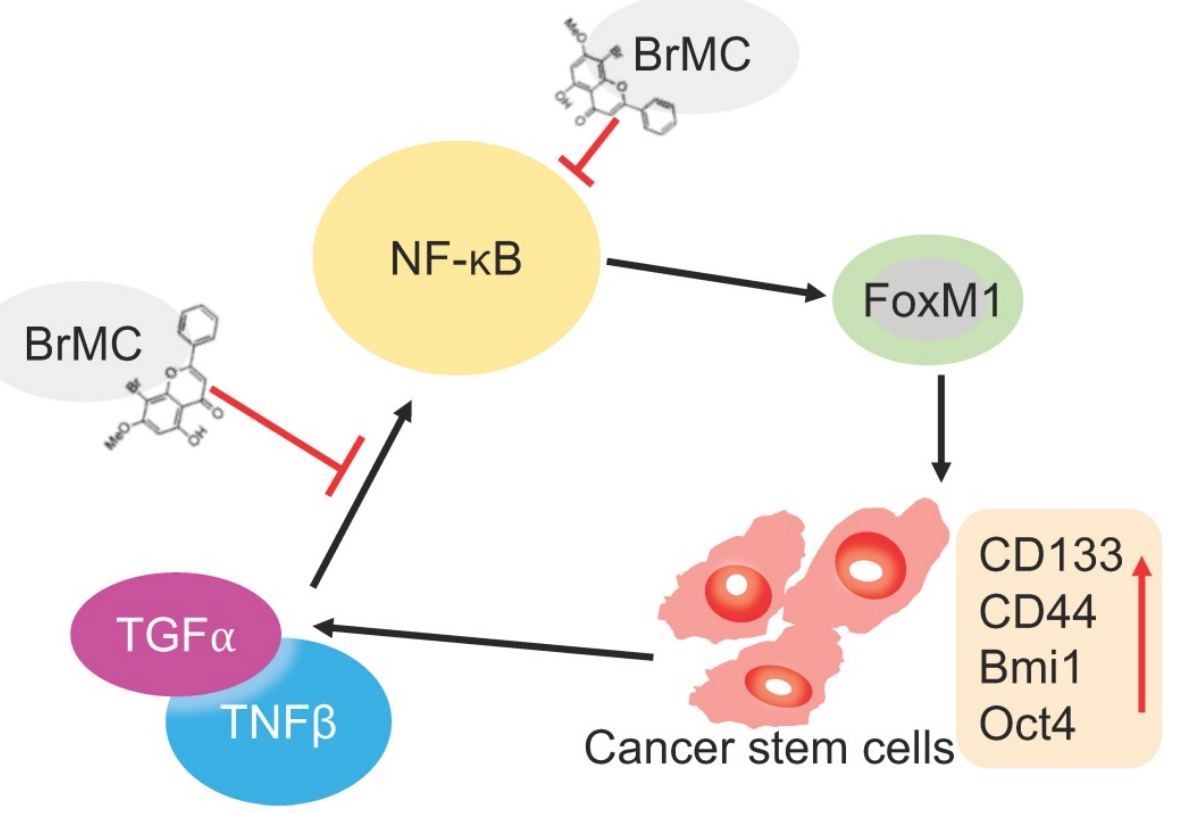

Figure 7. Illustration of BrMC function mechanism in targeting NSCLC-CSC via NF-KB/FoxMI signalling. Pro-inflammatory factors TNF- $\alpha$ and TGF- $\beta$ can promote the self-renewal capacity as well as activate NF-KB signalling in NSCLC-CSC, which also increase the expression of stem cell markers CD133, CD44, Bmil and Oct4. Alternatively, oncogenic transcriptional factor FoxMl works as downstream co-activators of NF-KB signalling to increase the self-renewal capacity of NSCLC-CSC. BrMC works as inhibitor of CSC through targeting NF- KB/FoxMl in does dependent manner.

\section{Discussion}

Studies have recently demonstrated that chronic inflammation-induced carcinogenesis and metastasis is a major challenge to cancer therapy, and elevated cytokines in chronic inflammation contribute to mortality in many malignancies, including NSCLC [32-34]. Understanding the mechanisms underlying induction of the metastasis and carcinogenesis by pro-inflammatory cytokines might lead to a novel therapeutic approach [35]. In this study, we first demonstrated that co-treatment of pro-inflammatory TNF- $\alpha$ and TGF- $\beta$ cooperatively promoted lung cancer stemness of NSCLC H460 cell line via NF-KB and FoxM1. In addition, we also revealed that BrMC, a novel synthetic analogue of dietary flavonoid chrysin significantly inhibited lung cancer stemness of NSCLC H460 cell line induced by pro-inflammatory cytokines through downregulating expression of NF-kB and FoxM1 proteins. These results presented in our experimental works indicated that the bidirectional activation of NF-kB and FoxM1 not only may be a key biological marker for promotion of lung cancer stemness, but also may be a molecular target for the inhibitory effects of BrMC on lung cancer stemness of NSCLC H460 cell line induced by pro-inflammatory cytokines.

Many studies have showed that TNF- $\alpha$ combined with chronic exposure to TGF- $\beta$ induces carcinogenesis of several tumors, including breast cancer [36] and cervical cancer [16]. We have previously demonstrated that TNF- $\alpha$ and TGF- $\beta$ associated EMT occurs via NF-kB-dependent transcriptional upregulation of Twist1. Here, we constructed the model for induction of lung cancer stemness, including elevated sphere-forming and colony forming capabilities, increased expression of CSC-associated markers (CD133 and CD44) and multipotential transcription factors (Bmi1 and Oct4) by chronic inflammation using co-treatment with TNF- $\alpha$ and TGF- $\beta$ to NSCLC H460 cells. Our study clearly showed that $\mathrm{H} 460$ cells administered TNF-a after prolonged induction by TGF- $\beta$ parallelly upregulated NF-kBp65 and FoxM1 protein expression. Consistently, the exposure to pro-inflammatory cytokines also leads to stemness, including sphere and colony formation, and CSC-associated protein expressions. Inhibition or overexpression of NF-kBp65 accordingly alters FoxM1 protein expression. Conversely, inhibition or overexpression of FoxM1 also accordingly alters NF-kBp65 protein expression. These results clearly demonstrate that bidirectional interaction of NF-KB with FoxM1 participates in pathogenesis of lung cancer under inflammatory microenvironment stimulated by TNF- $\alpha$ combined with TGF- $\beta$ (Fig. 7).

It is well known that NF-KB plays a significant role in many signaling pathways including those that are involved in cancer development and progression [37]. Disrupts the interplay of NF-kBp65 and FoxM1 could eradicate leukemia stem cells in chronic myelogenous leukemia. NF-kBp65 physically 
interacted with FoxM1, and was recruited to the FoxM1 gene promoter to increase the transcription of FoxM1 $[38,39]$. It showed that blocking the expression of NF-kBp65 and FoxM1 could inhibit the invasion and migration and increase the apoptosis of cancer cells [39]. Our previous data showed that 5-allyl-7-gen-difluoromethoxychrysin, a novel synthetic analogue of chrysin synergistically enhances TRAIL-mediated apoptosis in NSCLC cell line through upregulating DR5 expression [27]. Recently, we have reported that BrMC effectively inhibited CSC characteristics in hepatocellular carcinoma [26]. More recently, we showed that reversed M2 polarization of TAMs by inhibition of NF- $\mathrm{kB}$ activation [25]. In this study, we found that BrMC and SN50 alone or in combination could inhibit the expression of NF-kBp65 and FoxM1, sphere and colony formation and the expression of CD133, CD44, Bmi1 and Oct4 in H460 cells induced by pro-inflammatory cytokines, whereas, overexpression of NF-kBp65 almost abrogated the above effects of BrMC. These results demonstrated that inhibitory effects of BrMC on stemness of $\mathrm{H} 460$ cells induced by proinflammatory cytokines may be dependent on downregulation of NF-kBp65 expression (Fig. 7).

An increase of expression of FoxM1 is associated with the development and progression of many cancers, including breast, liver, prostate, brain, and lung cancers, whereas the ectopic expression of the FoxM1 accelerated the development, proliferation, and tumor growth in mouse models of prostate cancer [40]. Other studies showed that thiostrepton inhibited the proliferation, migration and transformation ability of breast cancer cells by down regulating FoxM1 expression [41]. In this study, we observed that treatment with BrMC and thiostrepton alone or in combination could inhibit the expression of NFkB-65 and FoxM1, sphere and colony formation and the expression of CD133, CD44, Bmi1 and Oct4 in H460 cells induced by pro-inflammatory cytokines, whereas, overexpression of FoxM1 almost abolished the above effects of BrMC. These results suggest that inhibitory effects of BrMC on stemness of H460 cells induced by proinflammatory cytokines may be dependent on downregulation of FoxM1 expression.

In summary, our results suggest that inflammatory factors TNF- $\alpha$ and TGF- $\beta$ enhance lung cancer stemness of $\mathrm{H} 460$ cells through NF-KB and FoxM1, and BrMC can inhibit those induced stemness through simultaneously inhibiting expression of NF-kB and FoxM1 (Fig. 7). BrMC is expected to become a promising candidate for the "updruggable" treatment of lung cancer.

\section{Supplementary Material}

Supplementary figures.

http://www.jcancer.org/v10p5244s1.pdf

\section{Acknowledgements}

This study was funded by the Projects of NSFC (No.30760248, No.81172375 and No.31400311), the Project of Scientific Research Fund of Hunan Provincial Education Department (No.14C0707), the Project of Hunan Provincial Natural Science Foundation (No.13JJ3061) and the Scientific Research Fund of Hunan Normal University (No.140668). This project also received financial support from Health and Family Planning Commission of Hunan Province (No. B2016091) and Open Grant of Key Laboratory of Study and Discovery of Small Targeted Molecules of Hunan Province (2019CG01).

\section{Competing Interests}

The authors have declared that no competing interest exists.

\section{References}

1. Siegel RL, Miller KD, Jemal A. Cancer statistics, 2019. CA Cancer J Clin. 2019; 69: 7-34.

2. Herbst RS, Morgensztern D, Boshoff $C$. The biology and management of non-small cell lung cancer. Nature. 2018; 553: 446-54.

3. Ettinger DS, Wood DE, Aisner DL, Akerley W, Bauman J, Chirieac LR, et al. Non-Small Cell Lung Cancer, Version 5.2017, NCCN Clinical Practice Guidelines in Oncology. J Natl Compr Canc Netw. 2017; 15: 504-35.

4. Boloker G, Wang C, Zhang J. Updated statistics of lung and bronchus cancer in United States (2018). J Thorac Dis. 2018; 10: 1158-61.

5. Siegel RL, Miller KD, Jemal A. Cancer statistics, 2018. CA Cancer J Clin. 2018; 68: 7-30

6. Brenner DR, Fanidi A, Grankvist K, Muller DC, Brennan P, Manjer J, et al. Inflammatory Cytokines and Lung Cancer Risk in 3 Prospective Studies. Am J Epidemiol. 2017; 185: 86-95.

7. Schoenhals JE, Seyedin SN, Anderson C, Brooks ED, Li YR, Younes AI, et al. Uncovering the immune tumor microenvironment in non-small cell lung cancer to understand response rates to checkpoint blockade and radiation. Transl Lung Cancer Res. 2017; 6: 148-58.

8. Chen Z, Xu Z, Sun S, Yu Y, Lv D, Cao C, et al. TGF-beta1, IL-6, and TNF-alpha in bronchoalveolar lavage fluid: useful markers for lung cancer? Sci Rep. 2014; 4: 5595 .

9. Saito A, Horie M, Nagase T. TGF-beta Signaling in Lung Health and Disease. Int J Mol Sci. 2018; 19: 2640.

10. Liu RY, Zeng Y, Lei Z, Wang L, Yang H, Liu Z, et al. JAK/STAT3 signaling is required for TGF-beta-induced epithelial-mesenchymal transition in lung cancer cells. Int J Oncol. 2014; 44: 1643-51.

11. Gong K, Guo G, Gerber DE, Gao B, Peyton M, Huang C, et al. TNF-driven adaptive response mediates resistance to EGFR inhibition in lung cancer. J Clin Invest. 2018; 128: 2500-18.

12. Ren KQ, Cao XZ, Liu ZH, Guo $\mathrm{H}$, Quan MF, Liu $F$, et al. 8-bromo-5-hydroxy-7-methoxychrysin targeting for inhibition of the properties of liver cancer stem cells by modulation of Twist signaling. Int J Oncol. 2013; 43: 1719-29.

13. Lopez J, Poitevin A, Mendoza-Martinez V, Perez-Plasencia C, Garcia-Carranca A. Cancer-initiating cells derived from established cervical cell lines exhibit stem-cell markers and increased radioresistance. BMC Cancer. 2012; 12: 48.

14. Zakaria N, Yusoff NM, Zakaria Z, Lim MN, Baharuddin PJ, Fakiruddin KS, et al. Human non-small cell lung cancer expresses putative cancer stem cell markers and exhibits the transcriptomic profile of multipotent cells. BMC Cancer. 2015; 15: 84.

15. Eramo A, Lotti F, Sette G, Pilozzi E, Biffoni M, Di Virgilio A, et al. Identification and expansion of the tumorigenic lung cancer stem cell population. Cell Death Differ. 2008; 15: 504-14.

16. Dong W, Sun S, Cao X, Cui Y, Chen A, Li X, et al. Exposure to TNFalpha combined with TGFbeta induces carcinogenesis in vitro via NF-kappaB/Twist axis. Oncol Rep. 2017; 37: 1873-82. 
17. Zakaria N, Mohd Yusoff N, Zakaria Z, Widera D, Yahaya BH. Inhibition of NF-kappaB Signaling Reduces the Stemness Characteristics of Lung Cancer Stem Cells. Front Oncol. 2018; 8: 166.

18. Gu L, Wang Z, Zuo J, Li H, Zha L. Prognostic significance of NF-kappaB expression in non-small cell lung cancer: A meta-analysis. PLoS One. 2018; 13 : e0198223.

19. Yuan B, Liu Y, Yu X, Yin L, Peng Y, Gao Y, et al. FOXM1 contributes to taxane resistance by regulating UHRF1-controlled cancer cell stemness. Cell Death Dis. 2018; 9: 562.

20. Xu N, Jia D, Chen W, Wang H, Liu F, Ge H, et al. FoxM1 is associated with poor prognosis of non-small cell lung cancer patients through promoting tumor metastasis. PLoS One. 2013; 8: e59412.

21. Fu Z, Cao X, Yang Y, Song Z, Zhang J, Wang Z. Upregulation of FoxM1 by MnSOD Overexpression Contributes to Cancer Stem-Like Cell Characteristics in the Lung Cancer H460 Cell Line. Technol Cancer Res Treat. 2018; 17: 1533033818789635.

22. Yang L, Dong Y, Li Y, Wang D, Liu S, Wang D, et al. IL-10 derived from M2 macrophage promotes cancer stemness via JAK1/STAT1/NF-kappaB/Notch1 pathway in non-small cell lung cancer. Int J Cancer. 2019; 145:1099-1110.

23. Wang S, Yan Y, Cheng Z, Hu Y, Liu T. Sotetsuflavone suppresses invasion and metastasis in non-small-cell lung cancer A549 cells by reversing EMT via the TNF-alpha/NF-kappaB and PI3K/AKT signaling pathway. Cell Death Discov. 2018; 4: 26.

24. Wamsley JJ, Kumar M, Allison DF, Clift SH, Holzknecht CM, Szymura SJ, et al. Activin Upregulation by NF-kappa B Is Required to Maintain Mesenchymal Features of Cancer Stem-like Cells in Non-Small Cell Lung Cancer. Cancer Research. 2015; 75: 426-35.

25. Sun S, Cui Y, Ren K, Quan M, Song Z, Zou H, et al. 8-bromo-7-methoxychrysin Reversed M2 Polarization of Tumor-associated Macrophages Induced by Liver Cancer Stem-like Cells. Anticancer Agents Med Chem. 2017; 17: 286-93.

26. Zheng $X$, Meng WD, Xu YY, Cao JG, Qing FL. Synthesis and anticancer effect of chrysin derivatives. Bioorg Med Chem Lett. 2003; 13: 881-4.

27. Xie ZH, Quan MF, Liu F, Cao JG, Zhang JS. 5-allyl-7-gen-difluoromethoxychrysin enhances TRAIL-induced apoptosis in human lung carcinoma A549 cells. BMC Cancer. 2011; 11: 322.

28. Zhang S, Yang X, Wang L, Zhang C. Interplay between inflammatory tumor microenvironment and cancer stem cells. Oncol Lett. 2018; 16: 679-86.

29. Liu F, Song SS, Yi Z, Zhang M, Li JL, Yang F, et al. HGF induces EMT in non-small-cell lung cancer through the hBVR pathway. Eur J Pharmacol. 2017; 811: 180-90.

30. Palmini G, Zonefrati R, Mavilia C, Aldinucci A, Luzi E, Marini F, et al Establishment of Cancer Stem Cell Cultures from Human Conventional Osteosarcoma. Jove-J Vis Exp. 2016; 116: 53884

31. Kalinichenko VV, Kalin TV. Is there potential to target FOXM1 for 'undruggable' lung cancers? Expert Opin Ther Targets. 2015; 19: 865-7.

32. Zhang X, Li N, Shao H, Meng Y, Wang L, Wu Q, et al. Methane limit LPS-induced NF-kappaB/MAPKs signal in macrophages and suppress immune response in mice by enhancing PI3K/AKT/GSK-3beta-mediated IL-10 expression. Sci Rep. 2016; 6: 29359.

33. Chen PJ, Wang YL, Kuo LM, Lin CF, Chen CY, Tsai YF, et al. Honokiol suppresses TNF-alpha-induced neutrophil adhesion on cerebral endothelial cells by disrupting polyubiquitination and degradation of IkappaBalpha. Sci Rep. 2016; 6: 26554.

34. Wang S, Lan F, Xia Y. IncRA ANCR Inhibits Non-Small Cell Lung Cancer Cell Migration and Invasion by Inactivating TGF-beta Pathway. Med Sci Monit. 2018; 24: 6002-9.

35. Korkaya H, Liu S, Wicha MS. Regulation of cancer stem cells by cytokine networks: attacking cancer's inflammatory roots. Clin Cancer Res. 2011; 17: 6125-9.

36. Li CW, Xia W, Huo L, Lim SO, Wu Y, Hsu JL, et al. Epithelial-mesenchymal transition induced by TNF-alpha requires NF-kappaB-mediated transcriptional upregulation of Twist1. Cancer Res. 2012; 72: 1290-300.

37. Karin M, Ben-Neriah Y. Phosphorylation meets ubiquitination: the control of NF-[kappa]B activity. Annu Rev Immunol. 2000; 18: 621-63.

38. Jin B, Wang C, Li J, Du X, Ding K, Pan J. Anthelmintic Niclosamide Disrupts the Interplay of p65 and FOXM1/beta-catenin and Eradicates Leukemia Stem Cells in Chronic Myelogenous Leukemia. Clin Cancer Res. 2017; 23: 789-803.

39. Arora R, Yates C, Gary BD, McClellan S, Tan M, Xi Y, et al. Panepoxydone targets NF-KB and FOXM1 to inhibit proliferation, induce apoptosis and reverse epithelial to mesenchymal transition in breast cancer. PLoS One. 2014; 9: e98370.

40. Kalin TV, Wang IC, Ackerson TJ, Major ML, Detrisac CJ, Kalinichenko VV, et al. Increased levels of the FoxM1 transcription factor accelerate development and progression of prostate carcinomas in both TRAMP and LADY transgenic mice. Cancer Res. 2006; 66: 1712-20.

41. Kwok JM, Myatt SS, Marson CM, Coombes RC, Constantinidou D, Lam EW. Thiostrepton selectively targets breast cancer cells through inhibition of forkhead box M1 expression. Mol Cancer Ther. 2008; 7: 2022-32. 